\title{
Produção de sentidos entre adolescentes sobre o cuidado de si na gravidez
}

Nayara Bueno de Araujo(a)

Edir Nei Teixeira Mandú(b)

Araujo NB, Mandú ENT. Production of meanings among adolescents about self care during the pregnancy. Interface (Botucatu). 2016; 20(57):363-75.

In prenatal care, professionals usually disregard the network of meaningproduction in adolescents about the process of caring of themselves during pregnancy. The study aims to evidence this network in a specific situation, with focus in the sources and references of adolescents' communities in poor areas of Cuiabá-MT, Brazil, as synthesized in a map. The qualitative study, was performed in 2014-2015, in 12 pregnant adolescents through focal groups, individual interviews, review of medical records and analysis based in the precepts and categories of Critical Discourse Analysis. The main discursive community of reference is the family, although health professionals, media and some acquaintances also mediate the construction of their discourses. Biomedical knowledge and care, expressed as risk control through preventive behavior practices, are respectively the most relevant source and voice among other options. The understanding of these particularities induces the professionals to search better ways of relating with adolescents and enlarging their autonomy.

Keywords: Health communication. Map of symbolism. Pregnancy in adolescence. Prenatal care.
No pré-natal, profissionais comumente desconsideram a rede de produção de sentidos de adolescentes sobre o cuidado de si na gravidez. Busca-se evidenciá-la em uma situação concreta, com foco nas fontes e comunidades de referência para adolescentes de áreas pobres de Cuiabá-MT, Brasil, sintetizadas em um mapa. Trata-se de estudo qualitativo, realizado entre 20142015, com 12 adolescentes grávidas, por meio de: grupo focal, entrevista individual, consulta a prontuários e análise baseada em preceitos e categorias da Análise de Discurso Crítica. A principal comunidade discursiva de referência das adolescentes é a família, embora profissionais de saúde, mídia e conhecidos também intermedeiem a construção de seus discursos. A cultura biomédica e o cuidado, como controle de riscos via comportamentos, são, respectivamente, as fontes e as vozes mais relevantes dentre outras concorrentes. Entender essas peculiaridades propicia ao profissional buscar melhores formas de relacionar-se com adolescentes e ampliar sua autonomia.

Palavras-chave: Comunicação em Saúde. Mapa do mercado simbólico. Gravidez na adolescência. Cuidado pré-natal.

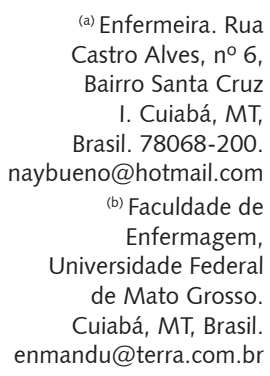

(a) Enfermeira. Rua Castro Alves, $n^{\circ} 6$, Bairro Santa Cruz I. Cuiabá, MT, Brasil. 78068-200. naybueno@hotmail.com

(b) Faculdade de Enfermagem, Universidade Federal de Mato Grosso. Cuiabá, MT, Brasil. enmandu@terra.com.br 


\section{Introdução}

Este estudo versa sobre a comunicação de adolescentes a respeito do cuidado de si na gestação, com ênfase nas fontes e comunidades discursivas de onde provêm seus discursos, às quais se dá visibilidade por meio do procedimento metodológico "mapa da comunicação".

O cuidado de si diz respeito à preocupação e ocupação das pessoas com elas mesmas, como um exercício social. Abarca o que as pessoas pensam, querem, assumem e fazem em prol de si mesmas. É parte de uma cultura de si, de alcance geral, que abrange atitudes e maneiras de se comportar, que impregnam socialmente as formas de viver e são traduzidas em procedimentos, práticas e receitas incorporados à vida das pessoas ${ }^{1}$. Neste trabalho nos interessa a aplicação desse conceito ao cuidado da própria saúde por adolescentes grávidas.

O mapa da comunicação², proposto por Inesita Soares de Araújo, é um recurso metodológico usado para representar, graficamente, a rede de produção social de sentidos a respeito de algo, por um determinado segmento populacional. Ele busca sintetizar discursos, fontes e fluxos de comunicação, com o objetivo de figurar a natureza social dessa produção e as vozes que nela se inter-relacionam e concorrem por dominância.

No pré-natal, observa-se que os profissionais ignoram a rede social de comunicação que adolescentes integram e que lhes serve de referência à construção de sentidos a respeito da saúde, da reprodução, do cuidado e de sua participação neste. Isto é, desconsideram as fontes e o entrelaçamento e a concorrência das ideias que subsidiam as ações de cuidado do grupo; e, por decorrência, simplificam o processo comunicacional com este frente. Isto é, ao lidarem com o cuidado, relacionam-se com adolescentes de forma ineficaz e impositiva, ainda que, muitas vezes, intencionem o contrário.

Pesquisa que analisa a consulta pré-natal do enfermeiro na Estratégia Saúde da Família (ESF), realizada em Cuiabá, caracteriza-a como uma prática burocrática (modelar, mecanizada), que naturaliza o processo reprodutivo e adota condutas de moralização e responsabilização de adolescentes pela gravidez, além de críticas aos seus comportamentos de cuidado de $\mathrm{si}^{3}$. O exame do pré-natal com adolescentes de um município da Bahia também identifica esse modelo normativo de ações, e a presença de relações impessoais que encobrem as especificidades da adolescência e gravidez ${ }^{4}$.

Essa forma de comunicação privilegiada na atenção à saúde das grávidas é refratária à dimensão social e política dos discursos e dos sentidos mobilizados por meio destes, seja os das adolescentes ou os dos profissionais. Mas, ela desconsidera que o processo comunicativo abriga um fluxo contínuo e multidirecional de informações e saberes (discursos com sentidos) que circulam entre as pessoas ou os grupos, e que são originados de fontes e comunidades discursivas variadas que competem entre si pela predominância de sentidos ${ }^{5,6}$.

A comunicação opera como um Mercado Simbólico(c), no qual os sentidos sociais (bens simbólicos) são produzidos, circulam e são consumidos pelos envolvidos (interlocutores), em um processo situado de disputas e negociações ${ }^{5}$.

Desse modo, os sentidos compreendem modos próprios e contextualizados de pessoas e grupos perceberem, classificarem e intervirem sobre o mundo, cuja construção se dá em rede, a partir de discursos circulantes 5 , que representam vozes em interação e concorrentes que veiculam diferentes pontos de vista, visões de mundo e ideias ${ }^{7}$ em função da conquista de poder simbólico ${ }^{5,6}$; ou seja, de poder na esfera dos sentidos sociais de falar e de ser ouvido, uma vez que este é exercido em primeira instância pela via discursiva e não se configura de forma igualitária ${ }^{8}$.

\footnotetext{
(c) A noção de comunicação como "Mercado Simbólico", proposta por Araújo ${ }^{8}$, baseia-se: no modelo produtivo de Verón, na teoria do poder simbólico de Bourdieu, na perspectiva da língua como arena dos embates sociais de Bakhtin e na microfísica do poder de Foucault.
} 
Nas diferentes sociedades, são vários os discursos sociais sobre a saúde das adolescentes, bem como sobre o processo reprodutivo delas e acerca dos cuidados que lhes são necessários, particularmente quando há uma gravidez em curso. Entre os diversos grupos sociais e, inclusive, entre os vários grupos de adolescentes, eles também possuem especificidades.

Os discursos são construídos e acionados a partir de espaços simbólicos em contínua atualização, como: o senso comum, a cultura popular, a ciência, a política, a religião e outros. Esses espaços constituem fontes de comunicação que organizam e produzem elementos simbólicos a partir do acervo individual, social e cultural pré-construído dos grupos ${ }^{5}$, o que remete à ideia de uma rede de comunicação.

As fontes representam comunidades discursivas - grupos de pessoas que produzem e fazem circular discursos peculiares por meio dos quais se reconhecem e são reconhecidos - que ocupam uma posição especificadora das instâncias ou dos espaços sociodiscursivos concretos estruturados como organizações ${ }^{5}$. Delas são exemplos: famílias, mídias, serviços de saúde, comunidades religiosas, grupos de adolescentes, entre outras. Uma comunidade discursiva situa os agentes institucionalmente e, também, os discursos das várias instituições. Essa instância possui a capacidade de produzir sentidos específicos, bem como de modificá-los ${ }^{6}$.

Dado o exposto, tem-se que os sentidos expressos por adolescentes, a respeito do cuidado de si na gravidez, são construídos socialmente a partir de discursos compartilhados por meio da comunicação com outras comunidades discursivas, segundo contextos diversos e específicos, e que são advindos de várias fontes e vozes em inter-relação, que, entre as adolescentes, manifestam-se com sentidos reforçados, contrapostos ou reinventados.

No pré-natal, quando os profissionais compreendem e consideram as referências das adolescentes, como elas são construídas e mobilizadas no contexto social e interativo, a lógica profissional deixa de ocupar espaço exclusivo. Abre-se espaço à apreensão do que pensam e a partir de quais fontes e de que modo constroem referências para a própria ação. Nessa perspectiva, configura-se maior possibilidade de o pré-natal ocorrer em bases humanizadas, dar suporte a necessidades de saúde mais abrangentes e desenvolver possibilidades de autonomia das adolescentes.

As fontes e comunidades discursivas representadas nos discursos delas sobre o cuidado da própria saúde, bem como a interação de várias vozes, neles presentes, de uma perspectiva de produção social dos sentidos, são aspectos inexplorados na literatura científica. Duas pesquisas com adolescentes puérperas, uma sobre o que conhecem acerca do cuidado do recém-nascido, sobre suas dificuldades e apoios recebidos ${ }^{9}$, e outra a respeito dos significados atribuídos a esse cuidado, ao autocuidado e às dificuldades encontradas ${ }^{10}$, concentram-se apenas na identificação e influência de agentes que atuam como suporte e ajuda no cuidado do filho.

Assim, buscando ampliar a abordagem do tema, este estudo enfoca de onde emanam os discursos de adolescentes sobre o cuidado de si na gestação, com o objetivo de conhecer e esquematizar as vozes, fontes e comunidades discursivas neles representadas e que caracterizam a rede social de produção de sentidos em torno do tema.

Busca-se simplificar o que compõe essa rede de sentidos, propiciar o entendimento de sua produção social e especificar que comunidades e vozes concorrem entre si pelo poder simbólico em torno do assunto. Além disso, intenciona-se contribuir para o entendimento, sobretudo do profissional do pré-natal, de que o seu discurso junto às adolescentes grávidas concorre com outros considerados pelas mesmas.

\section{Metodologia}

A pesquisa da qual deriva este trabalho é explicativa-qualitativa, e teve por objetivo compreender a construção da rede de sentidos sociais sobre a gestação e o cuidado de si na experiência, expressa em discursos de adolescentes que residiam em condições sociais adversas e cujo pré-natal realizava-se na ESF de Cuiabá, Mato Grosso.

A mesma foi realizada em quatro unidades da Regional Sul, segundo os seguintes critérios e razões: localização do estudo em uma regional em face da necessária articulação entre discurso e cenário; 
composição da equipe pré-natal com médico e enfermeiro para exploração da participação de ambos na construção dos sentidos sociais das adolescentes; mínimo de cinco adolescentes cadastradas por unidade da ESF, considerado o número encontrado de, no máximo, dez.

Participaram 12 adolescentes grávidas captadas nas unidades selecionadas. Nessa definição, considerou-se a repetição e a suficiência dos dados a partir da análise e classificação temática do material empírico da primeira etapa de recolha de dados ${ }^{11}$. Os atributos de interesse das participantes foram: idade entre 15 e 18 anos, pressupondo-se certa homogeneidade no grupo; mínimo de duas consultas de pré-natal, para captar o ponto de vista sobre este; idade gestacional de até 28 semanas, para evitar que a recolha coincidisse com o parto; e residência fixa nos territórios das unidades selecionadas.

As atividades empírico-analíticas ocorreram de abril a setembro de 2014. Utilizou-se a técnica de entrevista nas modalidades grupo focal e individual aberta, além de consulta aos prontuários das participantes. Na primeira etapa, realizaram-se dois encontros grupais, de uma hora cada um, em cada unidade; o primeiro para construir relações de confiança e para partilhamento das histórias de vida das adolescentes; o segundo para explorar ideias sobre a gravidez-maternidade e o cuidado de si. A entrevista individual ocorreu na segunda etapa, após a análise do material do grupo focal, e serviu para aprofundar, confirmar e esclarecer questões que emergiram da etapa anterior.

O tratamento dos dados fundamentou-se em duas dimensões e categorias correspondentes da Análise de Discurso Crítica'12: 1) prática discursiva (interdiscursividade, sentidos sociais, contexto existencial); e 2) prática social (ideologia e hegemonia). Organizou-se o corpus de análise; procedeuse à leitura repetida deste e o destaque dos enunciados e de outros dados de interesse; classificaramse os achados, com base na inferência e articulação empírico-teórica. Na síntese das vozes, fontes e comunidades discursivas da rede de sentidos do discurso das adolescentes, utilizou-se, como inspiração, o mapa da comunicação proposto por Araújo².

O estudo foi aprovado por Comitê de Ética em Pesquisa. Obteve-se a autorização das participantes e de seus responsáveis, por meio, respectivamente, do Termo de Assentimento e Termo de Consentimento Livre e Esclarecido. Respeitou-se a Resolução 466/2012/CNS. Atribuíram-se nomes fictícios às adolescentes.

\section{Resultados e discussão}

\section{Contexto existencial das adolescentes}

As adolescentes residiam em bairros periféricos na Região Sul de Cuiabá. Neles, vive um grande número de pessoas com baixa renda e baixa escolaridade, sendo predominantes, entre os responsáveis pelos domicílios, rendimentos mensais de até dois salários-mínimos e quatro a sete anos de escolaridade ${ }^{13}$.

A idade média delas era de 16,3 anos. Quatro eram solteiras e viviam com os pais, sendo que três delas mantinham o relacionamento com o namorado do qual engravidaram. Oito moravam com os companheiros e tinham relacionamento estável, sendo duas legalmente casadas. Quanto às famílias das adolescentes: quatro tinham pais casados e convivendo; quatro possuíam pais separados; entre duas, um dos pais havia falecido; uma desconhecia o pai, e uma não informou.

Em relação à escolaridade, quatro adolescentes cursavam o Ensino Médio, e uma o Ensino Fundamental. Seis tinham interrompido os estudos no Ensino Médio, duas antes, e quatro depois da gravidez. Apenas uma concluiu o segundo grau. Todas utilizavam ou utilizaram apenas a rede pública de ensino. Nenhuma exercia atividade remunerada; todas se ocupavam do cuidado da casa e dependiam financeiramente do companheiro ou da família.

Quanto à reprodução, sete adolescentes estavam na primeira gravidez, quatro na segunda e uma na terceira. Contudo, só duas tinham um filho anterior. Todas iam regularmente ao pré-natal na ESF e o iniciaram no primeiro trimestre da gestação, exceto uma. Nenhuma tinha histórico de problemas médicos anteriores ou em curso. 


\section{Discurso social de adolescentes sobre o cuidado de si na gestação: vozes, fontes e comunidades representadas}

Para as adolescentes do estudo, estar grávida requeria delas alguns cuidados com a saúde. Cuidar de si tinha basicamente o sentido de deixar de fazer determinadas coisas (por exemplo, comer alimentos considerados impróprios para a gestação e realizar atividades físicas que requeriam esforço) e incluir outras (como passar creme no abdômen e realizar o pré-natal), tendo em vista, sobretudo, a proteção da vida e saúde física do filho.

O repertório de cuidados valorizados pelas adolescentes tinha como referências expressivas: 1) pessoas próximas que Ihes ensinaram/ensinavam o que sabiam, e com as quais intencionavam continuar a aprender ou consultar em caso de necessidade; e 2) as próprias experiências reprodutivas e de cuidado anteriores. Contudo, nas falas delas, entrelaçavam-se fragmentos de outros discursos sociais em circulação, como discursos culturais e da ciência sobre a reprodução, acessíveis a elas de algum modo em seu contexto, recortados e reposicionados por elas - pela aceitação, recusa ou projeção. Assim, foi possível apreender, em seus discursos, determinadas vozes, fontes e comunidades discursivas de mediação.

A gestação é tida, culturalmente, como um acontecimento especial para a mulher, de efetivação de seu papel social materno e de realização pessoal, mas que, de acordo com a ciência médica, gera fragilidades em seu corpo e necessidades de controle da saúde. Medicamente, as adolescentes são consideradas ainda mais vulneráveis aos problemas de saúde e com maior precisão de controle. Assim, elas são expostas a discursos sociais de cuidado de algumas fontes e comunidades que buscam controlar a experiência na relação com a saúde-doença e em suas implicações para o nascituro.

Dentre as vozes presentes no discurso das adolescentes, encontrou-se a afirmação do ideal da maternidade, uma vez que o cuidado da própria saúde articulou-se sobremaneira à preocupação com a saúde do filho.

O cuidado da mulher/adolescente grávida em função da saúde do bebê é um argumento largamente utilizado pela biomedicina como justificativa para a atenção profissional em saúde reprodutiva e para a coparticipação da mulher. Esse argumento reproduzido entre as adolescentes é parte da incorporação da responsabilidade com o ser boa mãe, uma atribuição social e moral dada à mulher. Isto é, vincula-se à consecução do ideal de maternidade que requer amor e sacrifícios da mãe pelo filho e dedicação da vida a ele ${ }^{14}$.

Outras vozes importantes localizadas foram o necessário controle de riscos à saúde e a realização do cuidado como prevenção, valorizando-se práticas cotidianas dependentes da própria disposição, de disciplina e de ações médicas individuais, além da busca de recursos do sistema popular de cuidado à saúde, sobretudo, na insuficiência do primeiro.

Desse modo, identificou-se, no discurso das adolescentes, a participação de fontes como a cultura de gênero, a cultura familiar e popular/do lugar e a ciência biomédica. Essas fontes revelaram-se, sobretudo, por meio da comunidade discursiva família, e, com menor importância, por meio de profissionais da saúde, por membros da comunidade e mídias intermediadas por determinados meios de comunicação.

A família foi mencionada pelas adolescentes como a principal referência: para o que afirmavam saber, para se inteirarem do que julgavam não saber, para o que faziam ou o que afirmavam que precisavam saber/fazer para cuidar da própria saúde e do filho. Para tratar do assunto (gravidez, maternidade e cuidados), a mãe ou a sua substituta (madrinha, avó), que representam a comunidade discursiva família, foram as pessoas imediatas acessadas, ambas reconhecidas como referências de eleição antes mesmo da gravidez.

O postinho não teve muito pra me ensinar, pra me explicar. Não, porque minha mãe sempre me aconselhou; sempre me explicou. Então, não teve muito do pessoal do postinho... (Julia, 16 anos, primeira gestação) 
Eu converso com minha madrinha. [...] porque, assim, quando minha mãe faleceu, ela que me pegou pra criar. Assim, eu morava com meu pai, mas ficava mais na casa da minha madrinha e da minha vó. Aí converso mais com elas, sobre a gravidez. [...] Porque ela já passou por tanta experiência. (Ana, 17 anos, primeira gestação)

A competência atribuída à mãe/figura materna adveio do fato de ser mulher, de "ter mais" experiência e conhecimento que elas e de já ter vivenciado o evento da reprodução e de cuidado de filhos. Ou seja, o principal aspecto afirmado na construção do próprio saber-fazer em torno do cuidado de si foi o conhecimento oriundo da experiência acumulada do membro familiar, reforçado pelo fato de ser possível acessá-la de forma contínua, compreensível e imediata.

Converso com a mãe. Pelo fato de ela ser mais experiente. Ela também já passou por isso. Então ela sabe. Qualquer coisa que a gente sente - uma dor -, eu falo pra ela: "Ó mãe..." E ela: "É normal". "Ah mãe, to sentindo dor disso..." E ela: "É normal". Aí toda vez que eu tenho dúvida, essas coisas, eu pergunto pra ela, eu converso com ela [...]. (Carla, 17 anos, segunda gestação, segundo filho)

A importância dada à mãe condiz com achados de um estudo realizado no Paraná, com o objetivo de compreender a relação mãe e filha na construção da identidade na adolescência. Os autores identificam a importância atribuída àquela por adolescentes de escolaridade Média e Superior, para partilharem vivências marcantes. Também apontam que as mesmas dão grande valor à companhia e à ajuda materna e confiam na mãe, atribuindo a ela a condição de "mulher única e especial". Nas discussões consideram que a mãe constitui a principal figura de identificação das filhas, que as ajuda a compreenderem os seus papéis sociais e a própria feminilidade ${ }^{15}$.

Além disso, a mãe ou quem a substitui são vistas socialmente como tendo o papel de mediadoras entre a adolescente e os acontecimentos externos, sobretudo os especiais ${ }^{15}$, como a gravidezmaternidade e, por exemplo, o cuidado desta em serviços de saúde.

Desse modo, contribui para a eleição e afirmação da mãe, como interlocutora da principal fonte/ comunidade a respeito dos cuidados de saúde na gestação e dos cuidados do filho, o fato de a mesma estar próxima, disponível ou junto quando as adolescentes precisam da sua ajuda e o fato de ser considerada experiente, confiável, admirável e figura a ser espelhada.

Embora as adolescentes deste estudo identificaram-se, primeiramente, com a mãe, também deram importância a outras mulheres da família - avós, sogra, tias, irmãs - e, também, a homens da família - ao tio, marido e pai. Nesses casos, igualmente contribuiu para isso o reconhecimento de um saber derivado de suas experiências, o contato próximo e confiável e a demonstração de interesse e ajuda. Assim, as adolescentes constituíram os seus discursos com base em sentidos construídos em torno do papel da família na sociedade.

Minha sogra me ajuda bastante, também; tipo, se eu não sei de alguma coisa, eu pergunto pra ela; ela sabe, ela me ajuda. (Laura, 17 anos, primeira gestação)

Meu tio me ajuda também, em casa, meu tio também é experiente. Pergunto pra ele, pra minha mãe, minha vó. (Ingrid, 16 anos, segunda gestação, primeiro filho)

Quando eu posso, quando eu vejo a minha vó, eu converso com ela, pergunto algumas coisas. A minha vó já é mais velha, já sabe mais, tem experiência... Algumas coisas também falo com meu marido. Mais, assim... Mais é minha mãe mesmo, que tá o tempo todo do meu lado. (Julia, 16 anos, primeira gestação)

A família é representada como uma importante rede de proteção e segurança para os seus membros. Mesmo quando esses laços não são efetivos, a importância dela é considerada expressiva ${ }^{16}$. 
Desse modo, as referências discursivas e as práticas da família - de membros mulheres e homens - em torno da reprodução foram valorizadas pelas adolescentes. Não obstante, as referências de cuidado destas recaíram, sobretudo, sobre as mulheres da família, em face das suas experiências com o processo e, além disso, ao papel social que, tradicionalmente, exercem nas ações de cuidado da casa e da família.

O desempenho desse papel é historicamente atribuído à mulher, a despeito das mudanças atuais nessa compreensão sociocultural. Isto é, mulheres cuidam dos filhos e do que eles necessitam, acompanham mais de perto suas experiências, cuidam de sua saúde e, se necessário, mobilizam recursos médicos oficiais e não oficiais para atender necessidades nessa esfera. Daí serem referências importantes na construção dos discursos das adolescentes.

Embora a família fosse a principal comunidade de referência para os saberes e as práticas de cuidado à saúde das adolescentes, também mencionaram o contato com mídias, por intermédio dos meios de comunicação internet (computador) e televisão (TV), embora com menor ênfase. Na TV acessam novelas, filmes e reportagens:

Eu sou mais assim, pesquisar na internet. [...] Se eu tenho internet eu sou mais de pesquisar do que falar com as pessoas... (Diana, 18 anos, segunda gestação)

Também, a gente vê vários casos, né? De mãe que não cuida bem, não se alimenta; como o neném nasce, às vezes, prematuro; outro com algum problema. Eu vejo bastante isso, na televisão ou perto de casa mesmo eu vejo bastante. Aí, eu me cuido mais. (Ana, 17 anos, primeira gestação)

Estudo realizado na cidade do Rio de Janeiro, com dois grupos de jovens de configuração socioeconômica contrastante, para compreender o vivido por eles no que concerne à saúde, apontou que a mídia se fez presente em ambos os grupos ${ }^{17}$.

As comunidades discursivas dos grupos coincidiram em boa parte, apresentando diferenças sensíveis em relação à ênfase conferida a essas comunidades, relacionada claramente aos contextos de cada grupo. Analisando a mídia, particularmente a TV, as autoras apontaram a existência de uma concorrência discursiva, com alguns sentidos legitimados mais que outros.

Além do observado da vivência de outros da comunidade onde elas moram, também o experimentado pelas adolescentes influi em seus repertórios discursivos. Nesse sentido, a experiência prévia de cuidado de outras crianças/bebês foi valorizada por adolescentes como uma fonte a respeito do futuro cuidado do filho.

Ah, eu tô me sentindo (preparada), eu não vejo a hora que sai logo. [...] É porque eu já sou profissional no negócio [risos]. É porque eu já cuidei do meu irmão. Eu sempre trabalhei só de babá; eu sempre cuidei só de bebezinho [...]. (Ingrid, 16 anos, segunda gestação, primeiro filho)

A adolescente Carla, 17 anos, que enfrentou problemas médicos na sua primeira gravidez, considerou, a partir da própria experiência, a necessidade de concretizar os cuidados pré-natais em um serviço de saúde:

Eu tive (o primeiro filho) 10 horas da noite. No outro dia, oito horas eu já fui liberada. Aí todo dia eu ia lá, mas não gostava de ver ela assim. Porque só chorava. Com tudo aquilo de aparelho nela. [...] Eu já imaginava, por causa que o médico falou que a culpa era minha, que a chance de ela viver era zero. [...] Ele falou: "ah, que você qué falá? Você não sabe nem o sexo da criança, não fez nada. Olha só esse cartão aqui, só tem seu nome." [...] Ai entrei mais em desespero. Você já sabe que se a criança nascer antes do tempo a chance de viver também fica bem baixa. [...] Eu fui ver ela no outro dia, quando foi de manhã eles me ligaram do hospital falando que ela tinha falecido, que era pra ir lá pegar o corpo dela. Aí chorei muito, entrei em 
desespero. [...] Aí, desse agora (gravidez atual), desde o começo, quando descobri que tava grávida, já vim cuidar.

A experiência constitui um saber singular, que é distinto do saber científico, e configura-se na relação entre o conhecimento e a vida. Ela é uma espécie de mediação entre ambos ${ }^{18}$. Assim, a vida habitada é uma das fontes dos discursos das adolescentes, que também modela os sentidos que atribuem ao que necessitam e ao cuidado do filho e de si.

As experiências das adolescentes do estudo com os serviços de saúde eram iniciais, contudo, afirmaram cuidados do repertório biomédico, como: o pré-natal sistemático, a realização de alguns exames recomendados, em especial, o ultrassom; e o uso de medicamentos, como o sulfato ferroso, o ácido fólico, o paracetamol e outros.

O conhecimento científico foi uma das fontes dos discursos das adolescentes representada, sobretudo, pela comunidade discursiva dos profissionais do pré-natal. Dentre esses, deram destaque ao médico:

Ah, eu tiro (dúvidas) com o médico [...] Porque muita gente fala tanta coisa, a sua cabeça aí... Igual no meu caso, eu, alguns tempo atrás, tava tendo uma dor na região do "imbigo". Eu perguntava pra um, num sabia respondê, perguntava pra outro, num sabia respondê... Aí eu cheguei no médico e perguntei que que era isso que tava doendo, e eu tava inchando muito cedo... Aí ele falô: "seu inchaço é normal e esse negócio no imbigo é porque o nenê ta mexendo e conforme ele mexe ele puxa o cordão, aí dói" Ele falou que era normal. (Julia, 16 anos, primeira gestação)

Nesse fragmento, pode-se perceber o confronto a um dos discursos que valorizam - de pessoas de sua família ou de sua comunidade - tendo, por contraponto, referências do saber médico.

Embora profissionais sejam mencionados como uma das comunidades de referência para o cuidado à saúde entre as adolescentes, eles não são comunidades prioritárias nem exclusivas na construção dos sentidos entre elas, concorrendo com outras. Isso não significa que as adolescentes não tenham conhecimentos biomédicos como uma importante referência. Ideias relativas à alimentação saudável segundo meios científicos, por exemplo, encontradas em seus discursos, são divulgadas não só por serviços de saúde e seus trabalhadores, mas, também, por meios de comunicação, escolas e pessoas que têm contato com eles, como conhecidos da comunidade e membros da família.

Nesse sentido, fragmentos do repertório de cuidados médicos parecem ter uma influência importante na composição do discurso das adolescentes. Possivelmente as suas famílias os afirmem. Tanto que a mãe, principal referência das adolescentes, com a sua experiência e o seu saber próprio, mediou a inclusão de fragmentos do saber dos profissionais no discurso e prática das adolescentes.

Ingrid: minha mãe proibiu eu de tomar qualquer um remédio.

Gabi: eu tomo só o que a médica passou agora.

Helena: dor de cabeça, eu tomo paracetamol, a médica passou.

Ingrid: eu também. Minha mãe não deixa eu tomar, nem a pau. Ela quer perder a neta? [risos].

O discurso da comunidade família, que serve de base às adolescentes, assim como o discurso peculiar delas, é constituído na inter-relação e disputa de várias vozes, oriundas de variadas fontes e comunidades. Quer dizer, cada fonte e cada comunidade discursiva articulam o seu específico discurso em um processo de concorrência com outros saberes. O discurso médico-científico é hegemônico em nossa cultura, sendo veiculado por várias comunidades discursivas. Ele é popularizado, acessado pelas pessoas no contato com os serviços de saúde, pela mídia, nas escolas, dentre outras formas. 
Com as mudanças nas práticas de cuidado à saúde/saúde da mulher na história, a reprodução/ gestação deixou de ser um evento fisiológico, considerado normal, para se tornar institucionalizado, médico, normatizado. Desde os anos 1980, ao se ampliar, no país, a atenção à saúde da mulher, com ações educativas, preventivas, de diagnóstico e tratamento, estabeleceu-se um protocolo de ações de acompanhamento pré-natal nas unidades básicas de saúde ${ }^{19}$.

Assim, o cuidado de si na gestação passou a ser associado a essas ações, em especial, ao acesso à consulta médica, exames de controle, medicamentos, orientações e outros. Portanto, os sentidos construídos, pelas adolescentes do estudo, em torno dos cuidados profissionais estão conectados ao modelo de atenção hegemônico socialmente valorizado e ofertado, reafirmado por elas em alguns de seus componentes.

O cuidado de si também foi pensado e afirmado a partir de recursos do sistema de cuidado tradicional. Nos discursos das adolescentes, há ideias relacionadas a esse específico sistema, além do sistema médico e do familiar.

Eu também tive disso, problema no intestino, e eu ainda acho que o sulfato ferroso ajuda mais ainda, você tê mais pressão... Prendê... Daí cê sente aquela dor, igual esses dia eu levantei treis hora da manhã por causa de prisão de ventre e num dormi mais. [...] Aí tudo que o povo "ah aquilo ali é bão pro cê" se o povo falá que pedra é bão pra passá a dor, minha fia... eu to comeno [risos das meninas]. (Julia, 16 anos, primeira gestação)

Dentro do seu universo existencial, as adolescentes acessam e incorporam leituras diversas acerca de terapêuticas possíveis, que se mostram justapostas e, por vezes, antagônicas. As adolescentes estão muito próximas de conhecimentos e práticas tradicionais de cuidado à saúde nas comunidades onde vivem, têm contato direto com os recursos familiares, assim como estão sujeitas ao discurso médicocientífico que afirma o consumo sistemático de suas tecnologias.

A medicina tradicional é orientada por modelos culturais, religiosos e outros, e é produzida por agentes populares. Suas ações baseiam-se em produtos naturais e sobrenaturais. Já a medicina familiar orienta-se por prescrições profissionais e/ou populares e outras pessoais e familiares ${ }^{20}$.

Do conjunto dos discursos das adolescentes sobre o cuidado de si na gestação, é possível apreender a sua forte associação com a ideia de riscos e prevenção, por meio de mudanças comportamentais, pela afirmação de algumas ações médico-assistenciais do serviço básico de saúde, e, mesmo, de outros sistemas de cuidado, como o familiar.

De acordo com o discurso médico hegemônico, é em torno da ação da prevenção que as ações de saúde do nível local devem se pautar. Meios de comunicação e a escola também trabalham com esse enfoque, cuja preocupação volta-se, no caso dos adolescentes, aos seus estilos de vida.

A relação do ser humano com o futuro pode se pautar em pontos de vista tradicionais, mas a perspectiva científica de risco é cada vez mais vigorosa. Trata-se da proposição de um modo racional de pensar e agir que, no senso comum, imprime a fuga dos riscos (negativos) ou a busca de um estilo de vida mais sadio, administrado por cada um²1.

A divulgação dessas ideias e suas misturas têm largo espaço na mídia. Inúmeros riscos à saúde e comportamentos (relacionados com a alimentação, os exercícios físicos, entre outros) direcionados ao julgado controle daqueles são objetos de ação de educadores e pais, de programas de TV, de revistas para leigos, e resultam na oferta continuada de novos produtos e serviços. Essas ideias transpõem o ambiente sociocultural e constituem discursos e sentidos tais como os apresentados.

De forma sintética, no mapa da comunicação a seguir (Figura 1), sumarizam-se as vozes, fontes e comunidades discursivas reconhecidas na composição da rede de produção de sentidos de adolescentes em seus discursos sobre o cuidado de si na gestação. 


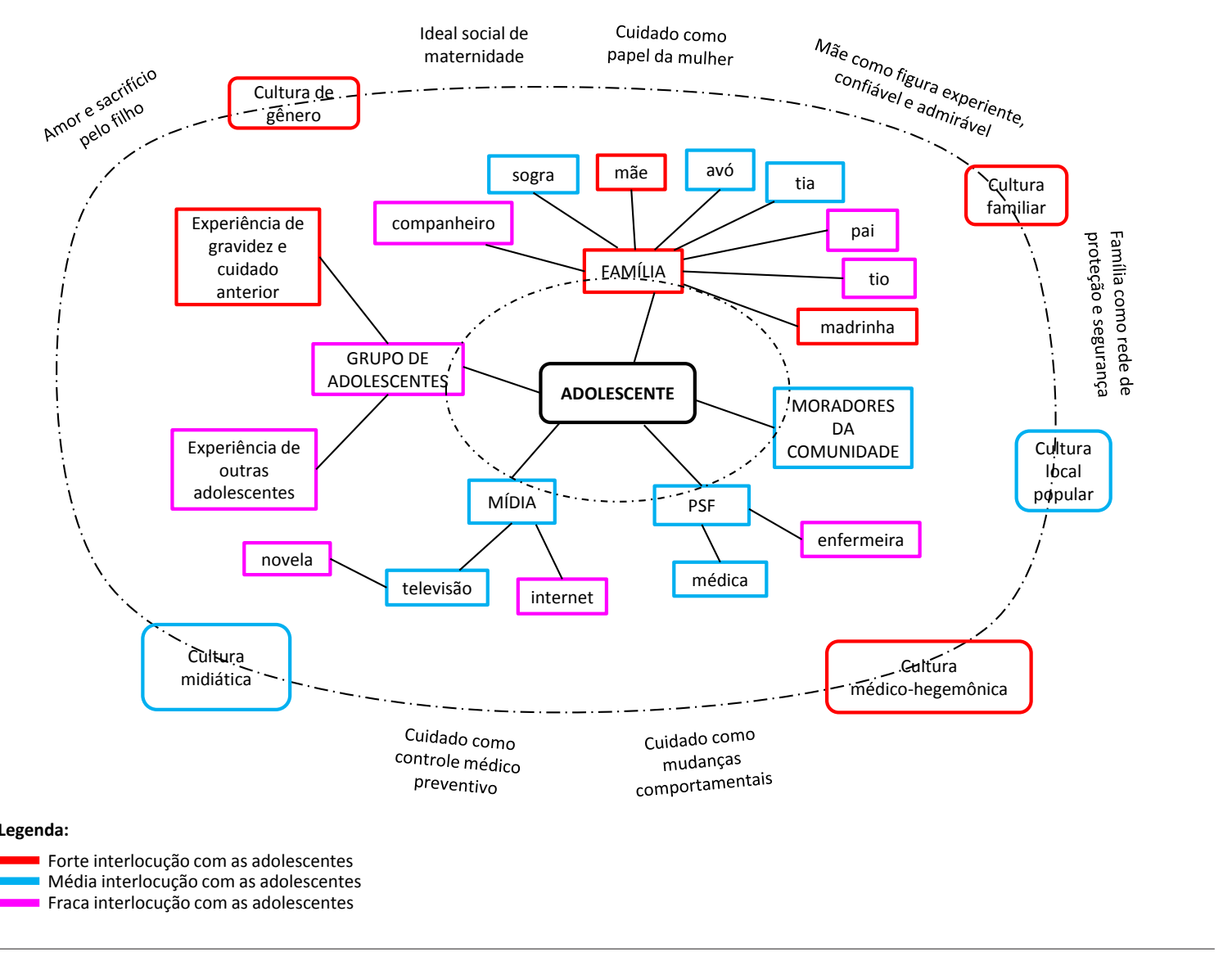

Figura 1. Mapa da comunicação sobre o cuidado de si de adolescentes grávidas: vozes, fontes e comunidades discursivas. Cuiabá, MT, Brasil.

Quando se põem em cena inúmeras articulações entre as várias comunidades discursivas, com os seus específicos discursos em torno de algo, tem-se expressa uma rede social de sentidos cuja articulação e embates, muitas vezes, não são percebidos em função da naturalização dos saberes. Entretanto, as várias vozes articuladas nos discursos correspondem a diferentes interesses, defesas e posições na estrutura social e, por essa razão, devem ser criticamente conhecidas ${ }^{6,8}$.

O cuidado pré-natal institucionalizado precisa considerar essas múltiplas vozes, fontes e comunidades que compõem a rede social de sentidos construídos pelas adolescentes a respeito do cuidado que necessitam, a fim de qualificar o cuidado ofertado a elas, em um contexto de reconstrução do modelo biomédico em direção ao modelo de atenção integral e humanizada. 


\section{Considerações finais}

Evidenciamos, neste estudo, a produção social dos discursos e sentidos de adolescentes grávidas sobre o cuidado de si por meio do mapa da comunicação. A principal comunidade discursiva de referência para as adolescentes é a família, sendo a mãe ou outra figura materna a sua principal representante. Os profissionais do pré-natal, onde elas acompanham a sua gravidez, não constituem uma comunidade importante para elas. Contudo, os cuidados científicos biomédicos, como o controle de riscos via práticas preventivas comportamentais, constituem, respectivamente, uma fonte e uma voz relevantes.

Assim, destacamos a necessidade de esta rede de produção de sentidos ser considerada, pelos profissionais de saúde, em suas ações assistenciais de Cuidado, assim como os contextos de vida e saúde nos quais as adolescentes interagem, em suas dimensões social, cultural e relacional, para que os serviços de saúde constituam-se em referências importantes para as várias necessidades de saúde daquelas.

Ressaltamos que, para compreender o discurso de adolescentes grávidas sobre o cuidado de si neste evento, é preciso situá-lo no contexto social e intersubjetivo correspondente e explicitar as vozes, fontes e comunidades discursivas nele presentes, reconhecendo o seu significado político. Os discursos dizem muito a respeito das ideologias e das práticas de poder, e funcionam não só na representação dos fenômenos, mas, também, na construção de relações sociais e na estruturação, reafirmação e contestação de hegemonias.

Nesse sentido, o mapa da comunicação pode ser usado como um instrumento de diagnóstico da saúde de adolescentes, pelos serviços e profissionais do pré-natal. A sua construção também pode ser um rico aliado no desenvolvimento de uma visão crítica sobre a gravidez e o cuidado a ela, não só para o profissional, mas, também, pelas próprias adolescentes e suas famílias, à medida que reconheçam de onde emanam os seus discursos, as relações de poder e de reprodução das desigualdades sociais que exprimem. Igualmente, pode ser usado como um instrumento de superação da visão tradicional de comunicação no campo da atenção à saúde e da educação, entre os profissionais em formação ou já inseridos no campo da prática com adolescentes.

\section{Colaboradores}

Os autores participaram, igualmente, de todas as etapas de elaboração do artigo. 


\section{Referências}

1. Foucault M. Histoire de la sexualité 3: Le souci de soi. Paris: Gallimard; 1984.

2. Araujo IS. O mapa da comunicação ou como deixar de olhar para o próprio umbigo e perceber a rede de sentidos da saúde. Niterói: Fundação Oswaldo Cruz. Centro de Informação Científica e Tecnológica, Núcleo de Pesquisa e Ensino em Comunicação e Saúde; 2006.

3. Jabra KL. Consulta de enfermagem de pré-natal na Saúde da Família em Cuiabá: reflexo burocrático e normalizador do social [dissertação]. Cuiabá (MT): Universidade Federal de Mato Grosso; 2013.

4. Melo MCP, Coelho EAC. Integralidade e cuidado a grávidas adolescentes na Atenção Básica. Cienc Saude Colet. 2011; 16(5):2549-58.

5. Araújo IS. Mercado simbólico: um modelo de comunicação para políticas públicas. Interface (Botucatu). 2004; 8(14):165-77.

6. Araújo IS. Contextos, mediações e produção de sentidos: uma abordagem conceitual e metodológica em comunicação e saúde. Rev Eletron Comun Inf Inov Saude. 2009; 3(3):42-50.

7. Bakhtin MM, Volochinov VN. Marxismo e filosofia da linguagem. 14a ed. São Paulo: Hucitec; 2010.

8. Araújo IS. Mercado simbólico: interlocução, luta, poder - um modelo de comunicação para políticas públicas [tese]. Rio de Janeiro (RJ): Universidade Federal do Rio de Janeiro; 2002.

9. Melo MM, Goulart BF, Parreira BDM, Machado ARM, Silva SR. O conhecimento de puérperas adolescentes sobre o cuidado com recém-nascidos. Cienc Cuid Saude. 2011; 10(2):266-73.

10. Silva LA, Nakano AMS, Gomes FA, Stefanello J. Significados atribuídos por puérperas adolescentes à maternidade: autocuidado e cuidado com o bebê. Texto Contexto Enferm. 2009; 18(1):48-56.

11. Fontanella BJB, Luchesi BM, Saidel MGB, Ricas J, Turato ER, Melo DG. Amostragem em pesquisas qualitativas: proposta de procedimentos para constatar saturação teórica. Cad Saude Publica. 2011; 27(2):389-94.

12. Fairclough N. Discourse and social change. Cambridge: Polity Press; 1999.

13. Prefeitura Municipal de Cuiabá. Secretaria Municipal de Desenvolvimento Urbano. Diretoria de Urbanismo e Pesquisa. Perfil socioeconômico de Cuiabá. Cuiabá: Central de Texto; 2012. v. 5.

14. Badinter E. Um amor conquistado: o mito do amor materno. Rio de Janeiro: Nova Fronteira; 1985.

15. Seron C, Milani RG. A construção da identidade feminina na adolescência: um enfoque na relação mãe e filha. Psicol Teor Prat. 2011; 13(1):154-64.

16. Portugal S. Famílias e redes sociais: ligações fortes na produção de bem-estar. Coimbra: Edições Almedina; 2014.

17. Serra GMA, Araujo IS, Santos EM. Comer com os olhos: discursos televisivos e produção de sentidos na promoção da saúde nutricional de adolescentes. Rev Eletron Comun Inf Inov Saude. 2012; 6(4):s.p.

18. Bondía JL. Notas sobre a experiência e o saber de experiência. Rev Bras Educ 2002; (19): $20-8$. 
19. Ministério da Saúde. Secretaria de Atenção à Saúde. Departamento de Ações Programáticas Estratégicas. Política nacional de atenção integral à saúde da mulher: princípios e diretrizes. Brasília (DF): Ministério da Saúde; 2004.

20. Teixeira E. Revisitando o cuidar cotidiano de saúde à luz do pensamento de Boaventura de Sousa Santos para tornar visível um espaço cuidativo. Esc Anna Nery Rev Enferm. 2003; 7(2):219-30.

21. Castiel LD, Guilam MCR, Ferreira MS. Correndo o risco: uma introdução aos riscos em saúde. Rio de Janeiro: Editora Fiocruz; 2010.

Araujo NB, Mandú ENT. Producción de sentidos entre adolescentes respecto al cuidado de sí durante el embarazo. Interface (Botucatu). 2016; 20(57):363-75.

Durante el prenatal, los profesionales en general tienden a desconsiderar la red de producción de sentidos de las adolescentes sobre el cuidado de sí durante el embarazo. En este artículo, se busca evidenciar esa red en situaciones concretas, con foco en fuentes y comunidades de referencia para adolescentes de áreas pobres de Cuiabá-MT, las cuales se hallan sintetizadas en un mapa. La información deriva de un estudio cualitativo, realizado a lo largo de 2014-2015, con 12 adolescentes embarazadas, y fue obtenida por medio de grupos focales, entrevistas individuales, consultas a registros médicos y análisis en preceptos y categorías de Análisis Crítico del Discurso. Aquí, es posible observar que la principal comunidad discursiva de referencia es la familia, aunque profesionales de salud, medios de comunicación y algunos conocidos también intermedien en la construcción de sus discursos. Los conocimientos biomédicos y el cuidado, como por ejemplo el control de riesgos en prácticas preventivas conductuales, son, respectivamente, la fuente y voz más relevantes encontradas dentro del estudio. Se afirma aquí que entender esas peculiaridades facilita al profesional la búsqueda de mejores formas de relacionarse con adolescentes y de ampliar su autonomía.

Palabras clave: Comunicación en Salud. Mapa del mercado simbólico. Embarazo adolescente. Atención Prenatal.

Submetido em 04/05/15. Aprovado em 21/09/15. 
